\section{Genetic Relationship of Ornamental Peach Determined Using AFLP Markers}

\author{
Dongyan Hu and Zuoshuang Zhang \\ Beijing Botanical Garden, Wofosi Road, Beijing, 100093, China
}

Donglin Zhang ${ }^{\mathbf{1}}$

Landscape Horticulture, Department of Plant, Soil and Environmental Sciences, University of Maine, Orono, ME 04469-5722

Qixiang Zhang

College of Landscape Horticulture, Beijing Forestry University, Beijing, 100083, China

\section{Jianhua Li}

Arnold Arboretum of Harvard University, 125 Arborway, Jamaica Plain, MA 02130

Additional index words. breeding, conservation, cultivar, DNA, identification.

\begin{abstract}
Ornamental peach (Prunus persica (L.) Batsch) is a popular plant for urban landscapes and gardens. However, the genetic relationship among ornamental peach cultivars is unclear. In this report, a group of 51 ornamental peach taxa, originated from $P$. persica and $P$. davidiana (Carr.) Franch., has been studied using AFLPs. The samples were collected from China, Japan, and US. A total of 275 useful markers ranging in size from 75 to 500 base pairs were generated using six EcoRI/MseI AFLP primer pairs. Among them, 265 bands were polymorphic. Total markers for each taxon ranged from 90 to 140 with an average of 120 . Two clades were apparent on the PAUP-UPGMA tree with $P$. davidiana forming an outgroup to $P$. persica, indicates that $P$. davidiana contributed less to the ornamental peach gene pools. Within $P$. persica clade, 18 out of 20 upright ornamental peach cultivars formed a clade, which indicated that cultivars with upright growth habit had close genetic relationship. Five dwarf cultivars were grouped to one clade, supported by $81 \%$ bootstrap value, indicating that they probably derived from a common gene pool. These results demonstrated that AFLP markers are powerful for determining genetic relationships in ornamental peach. The genetic relationships among ornamental cultivars established in this study could be useful in ornamental peach identification, conservation, and breeding.
\end{abstract}

Prunus persica (L.) Batsch (ornamental peach) is a small deciduous tree of Rose Family (Rosaceae). The plant has glabrous branchlets, serrulate leaves, and subsessile flowers blooming before the unfolded leaves during the early spring. The showy flowers range from pink to red, white, bicolor or tricolor. Growth habits range from upright, dwarf, weeping, to fastigiate. Leaf colors vary from green to purple $(\mathrm{Hu}$ et al., 2003). All these characteristics make the ornamental peach an excellent plant for urban landscapes and gardens.

Ornamental peach had been cultivated in China for thousands of years before it was introduced to western countries about three hundred years ago (Everett, 1967). Today it is grown in Asia, Europe, North America, South Africa, and Australia for its outstanding orna-

Received for publication 3 Apr. 2005. Accepted for publication 28 May 2005. Maine Agricultural and Forestry Experiment Station Publication 2812. We thank Todd Lasseigne, JC Rauslton Arboretum at North Carolina State University, and Masami Yamaguchi, National Institute of Fruit Tree Science of Japan, for providing plant materials.

${ }^{1}$ To whom reprint requests should be addressed; e-mail donglin@maine.edu. relationships for agronomic crops, fruit trees and ornamental plants, such as Cephalotaxus (Zhang et al., 2000), Dahlia (Debener, 2002), daylily (Tomkins et al., 2001), Dendranthema (Zhou and Dai, 2002), Dieffenbachia (Chen et al., 2004), Lagestroemia (Pooler, 2003), Philodendron (Devanand et al., 2004), plum (Goulao et al., 2001), Prunus mume (Ming and Zhang, 2003), and sweet cherry (Struss et al., 2001, 2003; Tavaud et al., 2001; Zhou et al., 2002).

Previous studies of fruiting peach cultivars (Aranzana et al., 2001, 2003; Dirlewanger et al., 1998; Manubens et al., 1999; Shimada et al., 1998) have shown that AFLP technique produces a high degree of polymorphic markers per assay, which could provide an efficient system for detection and analysis of fruiting peach cultivars.

In this study, therefore, AFLP was applied to estimate genetic relationships of ornamental peach taxa, providing insights into their classification and further breeding.

\section{Materials and Methods}

Plant materials. Fifty-one ornamental peach taxa, which originated from $P$. persica and $P$. davidiana, were used in this study. They were collected from the following botanical gardens and arboreta: Beijing Botanical Garden, Beijing, China (BBG), National Institute of Fruit Tree Science, Tsukuba, Japan (JAPAN), and the JC Raulston Arboretum at North Carolina State University, Raleigh, North Carolina, USA (JCRA) (Table 1). The relationships among these cultivars were described by $\mathrm{Hu}$ et al. (2003) based on their morphological features.

DNA extraction. Total genomic DNA was isolated from silica gel dried leaves using a DNeasy Plant Mini Kit (Qiagen Inc., Chatsworth, Calif.) and following the manufacturer's protocols. DNA concentration was quantified using an Eppendorf BioPhotometer (Brinkmann Instruments, Inc., Westbury, N.Y.). All DNA samples were diluted or concentrated to a uniform concentration of $80 \mu \mathrm{g} / \mathrm{mL}$ for the following AFLP procedures.

AFLP procedure. Amplified fragment length polymorphism restriction, ligation, and preselective amplification reactions were conducted according to the Perkin Elmer AFLP Plant Mapping Protocol (PE Applied Biosystems, Foster City, Calif.) with some modifications suggested by Zhang et al. (2000) except for using MseI adaptor sequence plus CAT, CTC combining with EcoRI adaptor sequence plus ACT, ACC, and AGG..Amplifications were electrophoresed at $3000 \mathrm{~V}$ and 50 ${ }^{\circ} \mathrm{C}$ for $2.5 \mathrm{~h}$ on an automated DNA Sequencer (model ABI 377; PE, Applied Biosystems). To avoid contamination from adjacent samples, the odd numbered lanes were first loaded, then the even numbered lanes were loaded after about one-minute run.

AFLP data analysis. For each primer combination, the amplified fragments were analyzed using GeneScan software (version 3.1. PerkinElmer,Applied Biosystems) equipped with ABI 377. The presence and absence of a specific 
marker were scored as 1 and 0 , respectively, for each sample, generating a data matrix. The data set was then imported to PAUP(PAUP 4.0, Swofford, 2002). Pairwise distance comparisons were calculated and phenetic trees were constructed using the unweighted pair group method with arithmetic average (UPGMA) in PAUP. Conversion to genetic distance $\mathrm{D}_{\mathrm{xy}}$, was obtained by the following equation: $D_{x y}=1-S_{x y}$ (data not presented) $\left[\mathrm{S}_{\mathrm{xy}}=2 \mathrm{~N}_{\mathrm{xy}} /\left(\mathrm{N}_{\mathrm{x}}+\mathrm{N}_{\mathrm{y}}\right)^{\mathrm{xy}}\right]$, where $\mathrm{S}_{\mathrm{xy}}$ is the genetic similarity between cultivar $\mathrm{x}$ and $y ; \mathrm{N}_{\mathrm{xy}}$ is the number of bands shared between cultivar $\mathrm{x}$ and $\mathrm{y}$; and $\mathrm{N}_{\mathrm{x}}$ and $\mathrm{N}_{\mathrm{y}}$ were the number of bands for cultivar $\mathrm{x}$ and $\mathrm{y}$, respectively.

\section{Results and Discussion}

In total, 275 markers, whose sizes ranged from 75 to 500 base pairs (bp), were generated using six EcoRI/Msel AFLP primer combinations of 51 ornamental peach taxa. Among them, 256 markers were polymorphic. The number of markers for each taxon ranged from 90 to 140 (mean $=120$, Table 2$)$.

Based on 275 usefulAFLP markers, genetic distances among the cultivars were found to be ranged from 0.044 to 0.404 (data not presented). The greatest distance $(0.404)$ was between $P$. davidiana 'BBG1' and $P$. persica 'Clarisse', 'Zhu Fen Chui Zhi', 'Genpaishidare', and 'Corinthian White', respectively. This result was not surprising given that genetic distances among the cultivars derived from different species are expected to be higher than those among the cultivars selected within a species.

Two major clades were recognized in the UPGMA tree, one being accessions of $P$. davidiana (CD), and the other containing cultivars of P. persica (CP) (Fig. 1). Prunus davidiana formed an outgroup to $P$. persica, which indicates that $P$. davidiana is genetically distant from other ornamental peach taxa derived from $P$. persica. The clade davidiana (CD) had three taxa derived from $P$. davidiana (P. davidiana var. alba, P. davidiana var. rubra, and $P$. davidiana 'BBG1') and supported by $100 \%$ bootstrap value. The genetic distance within these three taxa is 0.16 , while the average distance of these three taxa to all other taxa originated from $P$. persica is 0.339 . Obviously, these three taxa are closely related to each other compared with ornamental peach taxa derived from $P$. persica. Prunus davidiana 'BBG1', a new cultivar selected by Beijing Botanical Garden (manuscript in preparation), has upright twisted branches, single pink flowers, and a more narrow growth habit than the standard

Table 1. Taxa used in this study and their parentage and key characteristics.

\begin{tabular}{|c|c|c|c|}
\hline Taxon & Name & Parentage & Key characteristics \\
\hline 1 & Prunus persica 'Terutemomo'z & (Houki Momo × ‘Akashidara') $\mathrm{F}_{2}$ & Fastigiate, pink flower, double \\
\hline 2 & 'Corinthian Mauve'y & One seedling selected from 'NC174RL' $\times$ Pillar 271 & Fastigiate, rose pink flower, double \\
\hline 3 & 'Teruteshiro'y & (Houki Momo × ‘Sansetsu Shidare’) $F_{2}$ & Fastigiate, white flower, double \\
\hline 4 & 'Corinthian White'y & One seedling selected from 'NC174RL'” $\times$ Pillar 64 & Fastigiate, white flower, double \\
\hline 5 & ‘Corinthian Rose’y & One seedling selected from 'NC174RL' $\times$ Pillar 248 & Fastigiate, rose pink flower, red-leaved \\
\hline 6 & 'Corinthian Pink'y & One seedling selected from 'NC174RL' $\times$ Pillar 172 & Fastigiate, pink flower, red-leaved \\
\hline 7 & 'Houki Momo’z & Unknown & Fastigiate, pink and white flower, double \\
\hline 8 & 'Shiroshidare'z & 'Akashidare' OP seedlings selection & Weeping, white flower, single \\
\hline 9 & 'Lv E Chui Zhi’x & Unknown & Weeping, white flower, double \\
\hline 10 & 'Akashidare'z & Unknown & Weeping, red flower, single \\
\hline 11 & 'Hong Yu Chui Zhi'” & Unknown & Weeping, red flower, double \\
\hline 12 & 'Clarisse'y & Unknown & Weeping, pink flower, double \\
\hline 13 & 'Zhu Fen Chui Zhi'x & Unknown & Weeping, pink flower, double \\
\hline 14 & 'Dai Yu Chui Zhi’’ & Unknown & Weeping, light pink flower, double \\
\hline 15 & 'Genpaishidare’z & Unknown & Weeping, pink and white flower, single \\
\hline 16 & 'Yuan Yang Chui Zhi'” & Unknown & Weeping, pink and white flower, double \\
\hline 17 & ‘Wu Bao Chui Zhi’’ & Unknown & Weeping, pink and light pink flower \\
\hline 18 & 'Dan Ban Shou Fen'x & Unknown & Dwarf, pink flower, single \\
\hline 19 & 'Shou Fen'x & Unknown & Dwarf, pink flower, double \\
\hline 20 & 'Liang Fen Shou Xing'” & Unknown & Dwarf, bright pink flower, double \\
\hline 21 & 'Shou Bai’x & Unknown & Dwarf, white flower, double \\
\hline 22 & 'Dan Ban Shou Hong'x & Unknown & Dwarf, red flower, single \\
\hline 23 & 'Shou Hong'x & Unknown & Dwarf, red flower, double \\
\hline 24 & 'NCSU Dwarf Double Red'y & Unknown & Dwarf, pink flower, double \\
\hline 25 & 'Xia Yu Shou Xing'x & Unknown & Dwarf, pink and white flower, double \\
\hline 26 & 'Red Dwarf'z & ('Akame' × Juseito) $\mathrm{F}_{2}$ & Dwarf, pink flower, single, red-leaved \\
\hline 27 & 'Bonfire Patio'y & Tsukuba No.2 open-pollinated & Dwarf, pink flower, single, red-leaved \\
\hline 28 & 'Dan Fen'x & Unknown & Upright, pink flower, single \\
\hline 29 & 'Beijing $\mathrm{Zi}^{\prime}{ }^{\mathrm{x}}$ & Unknown & Upright, pink flower, single, red-leaved \\
\hline 30 & 'Dan Hong' ${ }^{\prime}$ & Unknown & Upright, red flower, single \\
\hline 31 & 'Dan Bai'x & Unknown & Upright, white flower, single \\
\hline 32 & 'Han Hong Tao'x & Unknown & Upright, red flower, double \\
\hline 33 & 'Er Se Tao’x & Unknown & Upright, pink flower, double \\
\hline 34 & 'Zan Fen’x & Unknown & Upright, pink flower, double \\
\hline 35 & 'Bi Таo'x & Unknown & Upright, pink flower, double \\
\hline 36 & 'Hong Bi Tao'x & Unknown & Upright, red flower, double \\
\hline 37 & 'Fei Tao'x & Unknown & Upright, red flower, double \\
\hline 38 & 'Wu Bao Tao'x & Unknown & Upright, pink red flower, double \\
\hline 39 & 'Ju Tao'x & Unknown & Upright, pink flower, double \\
\hline 40 & 'Kyou Maiko’y & Kikoumomo bud mutation & Upright, red flower, double \\
\hline 41 & 'Bai Bi Tao’x & Unknown & Upright, white flower, double \\
\hline 42 & 'Wan Bai Tao'x & Unknown & Upright, white flower, double \\
\hline 43 & 'Zi Ye Tao'x & Unknown & Upright, red flower, double, red-leaved \\
\hline 44 & 'BBG2’x & Mutation selected from 'Zi Ye Tao' & Upright, red flower, bicolor leaves red and green \\
\hline 45 & 'Unriu Momo’z & Nectarine mutation & Twisted twig, pink flower, single \\
\hline 46 & 'Bai Hua Shan Bi Tao'x & Unknown & Hybrid, white flower, double \\
\hline 47 & 'Fen Hua Shan Bi Tao'x & ('He Huan Er Se Tao’ × ‘Bai Hua Shan Bi Tao’) F & Hybrid, pink flower, double \\
\hline 48 & 'Fen Hong Shan Bi Tao'x & ('Jiang Tao’ × 'Bai Hua Shan Bi Tao’') $F_{2}$ & Hybrid, rose pink flower, double \\
\hline 49 & P. davidiana var. rubra ${ }^{\mathrm{x}}$ & Unknown & Pink flower, single \\
\hline 50 & P. davidiana 'BBG1'x & Selected from $P$. davidiana var. rubra & Fastigiate, pink flower, single \\
\hline 51 & P. davidiana var. alba ${ }^{\mathrm{x}}$ & Unknown & White flower, single \\
\hline
\end{tabular}


upright $P$. davidiana. The genetic distance between this new cultivar and the other two $P$. davidiana varieties is 0.16 (genetic similarity is 0.84 shown on Fig. 1).

The $P$. persica clade (CP) consisted of four subgroups, clade PR (red-leaved clade), clade PT (twisted clade), clade PU (upright clade), and clade PG [growth habit clade (including fastigiate, weeping, and dwarf)]. Clade PR included two red-leaved cultivars (' $\mathrm{Zi}$ Ye Tao' and 'BBG2'), with $100 \%$ bootstrap support. 'BBG2' is a bud-sport from the normal red-leaved ' $\mathrm{Zi}$ Ye Tao'. It was selected by Beijing Botanical Garden in 2001. Compared with normal red-leaved cultivars, 'BBG2' has unique purple and green bicolor leaves. The lowest genetic distance from this clone to ' $\mathrm{Zi}$ Ye Tao' was 0.12 .

The clade PT consisted only of cultivar 'Unriu Momo'. It is the only documented ornamental peach cultivar with twisted twigs. The plant was a mutant selected from nectarine seedlings (Yoshida et al., 2000). It is separate from all other ornamental peach taxa within the clade Persica (CP) in the UPGMA tree. The average genetic distance to other $P$. persica taxa is 0.237 . It is possible that this cultivar originated independently and might be an important germplasm source for further ornamental peach breeding.

Twenty taxa were clustered into the clade PU, which had the common morphological trait of upright branches. Eighteen out of 20 upright ornamental peach cultivars in this study were in this clade. Other growth habits, such as fastigiate (with narrow growth habit, columnar shape), weeping (with pendulous branches, umbrella shape), and dwarf (dense and compact, with short internodes and long narrow leaves), were mostly grouped to their relevant clade. These results demonstrate that growth habit probably is a hierarchy in ornamental peach systematics, supporting the conclusion from Hu et al. (2003).

Three hybrids, 'Bai Hua Shan Bi Tao', 'Fen Hua Shan Bi Tao', and 'Fen Hong Shan Bi Tao', were grouped into the clade PU. The average distance (0.192) of these three hybrids to other cultivars in the clade Persica (CP) is less than that to the clade Davidiana (0.254), but farther from other taxa in the clade Persica (CP).

The position of 'Bai Hua Shan Bi Tao', 'Fen Hua Shan Bi Tao', and 'Fen Hong Shan Bi Tao' in the PU clade supports the hybrid origin of these cultivars. Both 'Fen Hua Shan Bi Tao' and 'Fen Hong Shan Bi Tao' share 'Bai Hua Shan Bi Tao' (Hu and Zhang, 2001) as the pollen parent. The female parent of 'Fen Hua Shan Bi Tao' was 'He Huan Er Se Tao' (upright type, double, pink flowers) and the female parent of 'Fen Hong Shan Bi Tao' was 'Jiang Tao' (upright type, double, red flowers). According to the UPGMA tree, these cultivars have a closer relationship to $P$. persica than $P$. davidiana. 'Bai Hua Shan Bi Tao' shares 28 bands with 'Bai Bi Tao' and 11 bands with $P$. davidiana var. alba. Together, these three taxa share 61 bands in six primer combinations (Table 3). This result supports the conclusion drawn by Zhang et al. (1997) and Zhang (1998) that P. persica 'Bai Hua Shan Bi Tao' probably is a hybrid of $P$. persica 'Bai Bi Tao' and $P$. davidiana var. alba.

The two red-leaved dwarf cultivars 'Red Dwarf' and 'Bonfire Patio' clustered with the upright clade (PU), suggesting that upright cultivars may have been involved in the breeding and development of these dwarf cultivars. 'Red Dwarf', released by Yoshida and Seike (1974) in Japan, originated from hybridization of a red-leaved, upright parent and a green-leaved, dwarf peach. 'Bonfire Patio', released by Moore et al. (1993) in US, is an open pollinated seedling from a red-leaved upright type cultivar. Its closest relative is 'Beijing Zi', which is a red-leaved upright type cultivar. The morphological characters of 'Beijing Zi' are similar to the parent of 'Bonfire Patio'. The AFLP data is consisted with known origin of these two red-leaved cultivars, indicating that AFLP is a useful tool to elucidate putative breeding history of ornamental peach cultivar.

'Red Dwarf', 'Bonfire Patio', 'Beijing Zi', and 'Dan Fen' all have single pink flowers, while $P$. persica 'Dan Hong' has single red flowers and 'Dan Bai' has single white flowers. These six cultivars clustered as a subgroup in the PU clade (Fig. 1). The other 11 double flowered cultivars were clustered into another subgroup. AFLP data suggest that the number of petals can be used to subcategorize ornamental peaches.

Within the clade PG there were two subgroups, the clade PGD (dwarf clade) and the clade PGM (mixed clade of fastigiate, weeping, and dwarf; Fig. 1). The clade PGD included five

Table 2. Useful AFLP bands for 51 ornamental peach taxa.

\begin{tabular}{|c|c|c|c|c|c|c|c|}
\hline Taxon $^{z}$ & $\begin{array}{l}\text { E-ACT/ } \\
\text { M-CAT }\end{array}$ & $\begin{array}{l}\text { E-AGG/ } \\
\text { M-CAT }\end{array}$ & $\begin{array}{l}\text { E-ACC/ } \\
\text { M-CAT }\end{array}$ & $\begin{array}{l}\text { E-ACT/ } \\
\text { M-CTC }\end{array}$ & $\begin{array}{l}\text { E-AGG/ } \\
\text { M-CTC }\end{array}$ & $\begin{array}{l}\text { E-ACC/ } \\
\text { M-CTC }\end{array}$ & Total \\
\hline 1 & 24 & 20 & 11 & 18 & 17 & 18 & 108 \\
\hline 2 & 30 & 19 & 27 & 18 & 18 & 15 & 127 \\
\hline 3 & 28 & 22 & 23 & 19 & 17 & 18 & 127 \\
\hline 4 & 31 & 23 & 30 & 18 & 15 & 15 & 132 \\
\hline 5 & 26 & 23 & 29 & 19 & 16 & 18 & 131 \\
\hline 6 & 26 & 17 & 28 & 18 & 18 & 14 & 121 \\
\hline 7 & 25 & 22 & 32 & 19 & 17 & 17 & 132 \\
\hline 8 & 25 & 20 & 33 & 18 & 18 & 14 & 128 \\
\hline 9 & 25 & 19 & 25 & 15 & 13 & 13 & 110 \\
\hline 10 & 30 & 18 & 23 & 19 & 16 & 15 & 121 \\
\hline 11 & 31 & 19 & 25 & 17 & 22 & 17 & 131 \\
\hline 12 & 21 & 17 & 25 & 20 & 18 & 15 & 116 \\
\hline 13 & 27 & 18 & 27 & 18 & 20 & 14 & 124 \\
\hline 14 & 26 & 18 & 28 & 19 & 15 & 14 & 120 \\
\hline 15 & 31 & 17 & 25 & 17 & 19 & 17 & 126 \\
\hline 16 & 22 & 22 & 25 & 20 & 15 & 19 & 123 \\
\hline 17 & 23 & 21 & 23 & 18 & 20 & 16 & 121 \\
\hline 18 & 13 & 18 & 24 & 19 & 18 & 18 & 110 \\
\hline 19 & 8 & 18 & 25 & 14 & 20 & 15 & 100 \\
\hline 20 & 24 & 17 & 29 & 11 & 17 & 15 & 113 \\
\hline 21 & 7 & 18 & 20 & 19 & 20 & 18 & 102 \\
\hline 22 & 11 & 17 & 22 & 17 & 19 & 15 & 101 \\
\hline 23 & 9 & 18 & 21 & 19 & 19 & 18 & 104 \\
\hline 24 & 26 & 17 & 28 & 17 & 19 & 15 & 122 \\
\hline 25 & 22 & 16 & 26 & 19 & 19 & 18 & 120 \\
\hline 26 & 28 & 20 & 26 & 16 & 18 & 14 & 122 \\
\hline 27 & 30 & 21 & 32 & 19 & 18 & 17 & 137 \\
\hline 28 & 27 & 18 & 26 & 16 & 20 & 14 & 121 \\
\hline 29 & 29 & 27 & 27 & 19 & 20 & 18 & 140 \\
\hline 30 & 29 & 17 & 30 & 15 & 19 & 12 & 122 \\
\hline 31 & 30 & 16 & 20 & 9 & 17 & 11 & 103 \\
\hline 32 & 28 & 22 & 20 & 20 & 19 & 12 & 121 \\
\hline 33 & 26 & 21 & 22 & 20 & 18 & 10 & 117 \\
\hline 34 & 25 & 21 & 24 & 18 & 13 & 10 & 111 \\
\hline 35 & 30 & 23 & 22 & 19 & 18 & 10 & 122 \\
\hline 36 & 29 & 21 & 27 & 17 & 18 & 10 & 122 \\
\hline 37 & 24 & 21 & 24 & 19 & 17 & 10 & 115 \\
\hline 38 & 23 & 23 & 17 & 17 & 21 & 11 & 112 \\
\hline 39 & 34 & 21 & 19 & 19 & 21 & 13 & 127 \\
\hline 40 & 33 & 22 & 21 & 17 & 19 & 12 & 124 \\
\hline 41 & 29 & 23 & 26 & 18 & 19 & 10 & 125 \\
\hline 42 & 29 & 23 & 27 & 18 & 17 & 12 & 126 \\
\hline 43 & 35 & 27 & 21 & 18 & 19 & 12 & 132 \\
\hline 44 & 39 & 30 & 15 & 20 & 22 & 7 & 133 \\
\hline 45 & 36 & 28 & 30 & 18 & 16 & 11 & 139 \\
\hline 46 & 35 & 19 & 15 & 16 & 15 & 7 & 107 \\
\hline 47 & 33 & 18 & 21 & 19 & 21 & 9 & 121 \\
\hline 48 & 22 & 20 & 34 & 16 & 20 & 11 & 123 \\
\hline 49 & 23 & 25 & 16 & 14 & 19 & 7 & 104 \\
\hline 50 & 21 & 26 & 4 & 14 & 17 & 8 & 90 \\
\hline 51 & 23 & 28 & 17 & 14 & 18 & 9 & 109 \\
\hline Mean & 26 & 20 & 24 & 18 & 18 & 13 & 119 \\
\hline Markers & 81 & 53 & 52 & 30 & 37 & 22 & 275 \\
\hline
\end{tabular}

${ }^{2}$ The taxon number corresponds with the number in the first column of Table 1. 
dwarf cultivars ('Dan Ban Shou Fen', 'Shou Fen', 'Shou Bai', 'Dan Ban Shou Hong', and 'Shou Hong') and had 81\% bootstrap support. The average distance between these five dwarf cultivars is 0.085 . All of these five cultivars are very dense and compact, with short internodes, long narrow leaves. The results show that these five dwarf cultivars are more closely related to each other than to other cultivars. They probably share common germplasm.

All seven fastigiate cultivars and 10 weeping cultivars examined in this study clustered into the PGM subgroup. 'Terutemomo', 'Teruteshiro', and 'Houki Momo' are from Japan. The first two cultivars were released by Yamazaki et al. (1987). 'Houki Momo' is an ancient and unique cultivar from the Edo Era in Japan (Yoshida et al., 2000). 'Terutemomo'

Fig. 1. UPGMA tree of 51 ornamental peach taxa based on AFLP markers. was derived from a cross of 'Houki Momo' and 'Akashidare' (clustered into the PGM as well). 'Teruteshiro' was derived from a cross of 'Houki Momo' and a weeping habit cultivar with double pink flowers, which has very similar morphological characters to ' $\mathrm{Zhu}$ Fen Chui Zhi' (also in the PGM as well). 'Corinthian Mauve', 'Corinthian White', 'Corinthian Rose', and 'Corinthian Pink' are four column-shaped cultivars released by Werner et al. (2000a, 2000b, 2000c, 2001). They are derived from 'Houki Momo'. 'Shiroshidare' is an open pollinated seedling from 'Akashidare' (Yoshida et al., 2000). 'Genpaishidare' is from the National Institute of Fruit Tree Science, Tsukuba, Japan. 'Clarisse' is from the JC Raulston Arboretum at North Carolina State University, Raleigh, North Carolina, US. 'LvE Chui Zhi', 'Dai Yu Chui Zhi', 'Yuan Yang Chui Zhi', 'Hong Yu Chui Zhi', and 'Wu Bao Chui Zhi' are from Beijing Botanical Garden, China.
All these 17 weeping and fasitigiate cultivars were clustered in one clade, suggesting that the cultivars with weeping and fastigiate growth habits have closer genetic relationships.

The cultivars with similar flower colors and flower types were scattered in different clades. 'Kyou Maiko' (double red flowers) was a bud mutation from 'Ju Tao' (double pink flowers; Yoshida et al., 2000). The distance between these two cultivars was 0.055 . Both have narrow, chrysanthemum-like petals. The distance between 'Zan Fen' (double pink, peony-like flowers) and 'Fei Tao' (double pink, peony-like flowers) is 0.076. Within the dwarf clade, the distance between 'Shou Bai' (double white flowers) and 'Shou Hong' (double red flowers) was 0.044 . Within the mixed clade (PGM), the distance between 'Hong Yu Chui Zhi' (weeping, double red flowers) and 'Zhu Fen Chui Zhi' (weeping, double pink flowers) was 0.055 . No distinguished cluster was formed from the

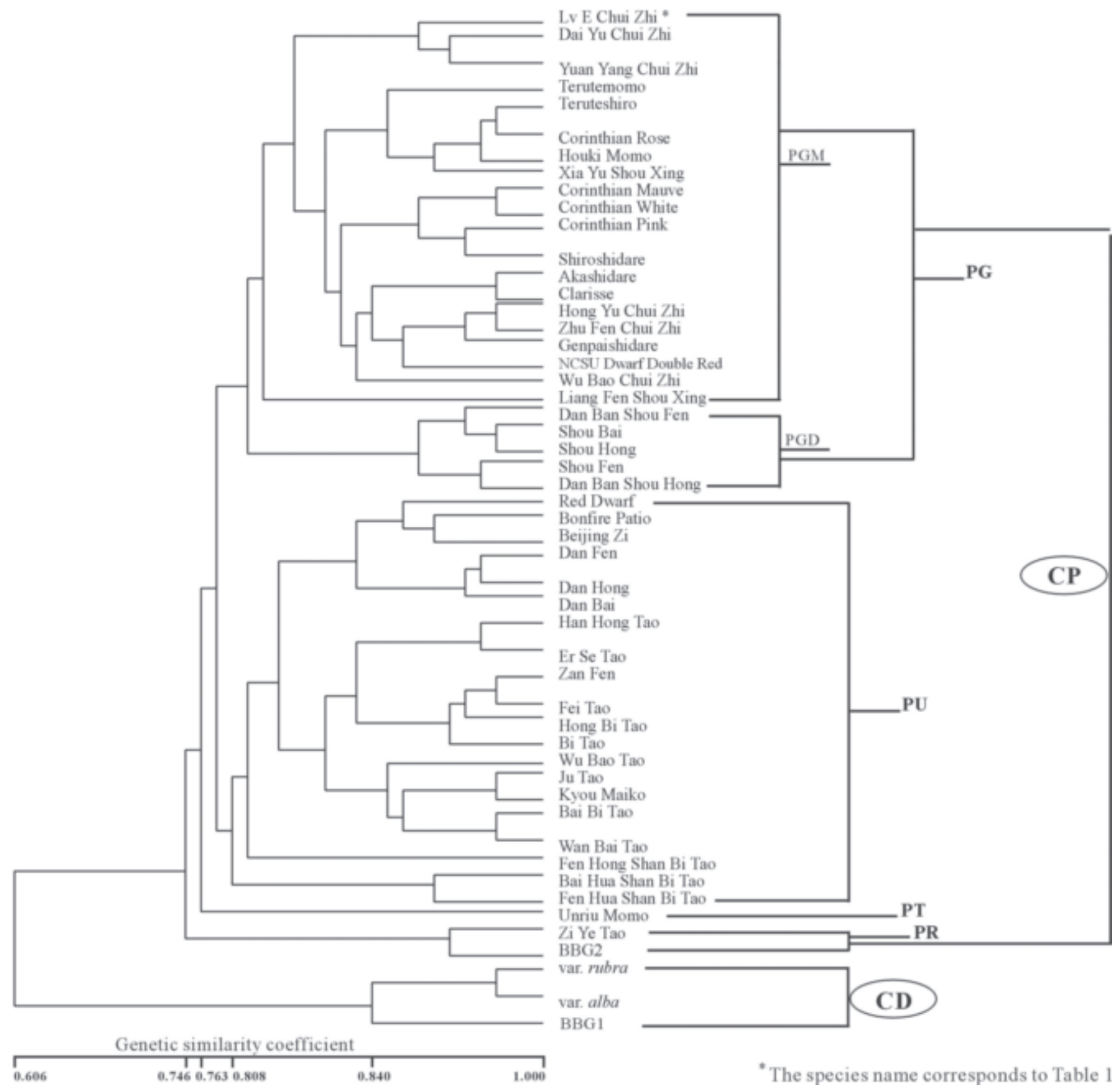




\begin{tabular}{|c|c|c|c|c|c|}
\hline Primer & $\begin{array}{c}\text { Total bands of } \\
\text { P. persica } \\
\text { 'Bai Hua Shan Bi Tao' }\end{array}$ & $\begin{array}{l}\text { Shared bands } \\
\text { with only } \\
\text { P. persica } \\
\text { 'Bai Bi Tao' }\end{array}$ & $\begin{array}{c}\text { Shared bands } \\
\text { with only } \\
\text { P. davidiana var. alba }\end{array}$ & $\begin{array}{l}\text { Shared bands with } \\
\text { both } P \text {. persica } \\
\text { 'Bai Bi Tao' and } \\
\text { P. davidiana var. alba }\end{array}$ & $\begin{array}{c}\text { Unique bands } \\
\text { not present in } \\
\text { P. persica } \\
\text { 'Bai Bi Tao' or } \\
\text { P. davidiana var. alba }\end{array}$ \\
\hline E-AGG/M-CAT & 19 & 3 & 0 & 16 & 0 \\
\hline E-ACC/M-CAT & 15 & 2 & 0 & 12 & 1 \\
\hline E-ACT/M-CTC & 16 & 4 & 1 & 10 & 1 \\
\hline Total & 107 & 28 & 11 & 61 & 7 \\
\hline
\end{tabular}

same flower color or type. This AFLP result indicates that flower color and type might not be useful in the classification of ornamental peaches.

\section{Conclusion}

AFLP fingerprinting data generated from this study provide a picture of genetic relationships of ornamental peaches. Ornamental peach taxa are mostly derived from $P$. persica. However, $P$. davidiana may have also been involved in ornamental peach cultivars' breeding and development. Both the growth habit and the number of petals are important characters in the systematics of ornamental peaches. Results of this study will likely provide guidance for future germplasm collection, conservation, and breeding of ornamental peaches.

\section{Literature Cited}

Aranzana, M.J., M.C. Vicente, and P. Arus. 2001. Comparison of fruit and leaf DNA extracts for AFLP and SSR analysis in Peach (Prunus persica). Acta Hort. 546:297-300.

Aranzana, M.J., J. Carbo, and P. Arus. 2003. Using amplified fragrant-length polymorphisms (AFLPs) to identify peach cultivars. J. Amer. Soc. Hort. Sci. 128:672-677.

Chen, J., R.J. Henny, D.J.Norman, P.S. Devanand, and C.C.T. Chao. 2004. Analysis of genetic relatedness of Dieffenbachia cultivars using AFLP markers. J. Amer. Soc. Hort. Sci. 129:81-87.

Debener, T. 2002. Molecular markers as a tool for analysis of genetic relatedness and selection on ornamentals, p. 329-345. In: A. Vainstein (ed.). Breeding for ornamentals: classical and molecular approaches. Kluwer Academic Publishers, London, U.K.

Devanand, P.S., J. Chen, R.J. Henny, and C.C.T. Chao. 2004. Assessment of genetic relationships among Philodendron cultivars using AFLP markers. J. Amer. Soc. Hort. Sci. 129:690-697.

Dirlewanger, E., S. Duha, M.A. Viruel, and R. Saunier. 1998. Identification of peach varieties using molecular markers. Acta Hort. 465:69-78.

Dirr, M.A.1998. Manual of woody landscape plants: their identification, ornamental characteristics, culture, propagation and uses. 5th ed. Stipes Publishing, Champaign, Ill.

Everett, T.H. 1967. New illustrated encyclopedia of gardening. N.Y. Bot. Garden Press, New York.

Goulao, L., L. Monte-Corvo, and C.M. Oliver. 2001. Phenetic characterization of cultivars of plum (Prunus sp.) by high multiplex ratio markers: Aplified fragment length polymorphism and inter-simple sequence repeats. J. Amer. Soc. Hort. Sci.126:72-77.

Hu, D. and X. Zhang. 2001. Breeding of early ornamental peach cultivars (In Chinese). J. Beijing For. Univ. 23:39-40.

Hu, D., Z.Zhang, X.Zhang, and Q. Zhang. 2003. The Germplasm preservation of ornamental peach cultivars. Acta Hort. 620:395-402.

Jacobson, A.L. 1996. North American landscape trees. Ten Speed Press, Berkeley, Calif.

Krussmann, G. 1986. Manual of cultivated broadleaved trees and shrubs. Timber Press, Portland, Ore.

Manubens, A., S. Lobos, Y. Jadue, M. Toro, R. Messina, M. Liadser, and D. Seelenfreund. 1999. DNA isolation and AFLP fingerprinting of nectarine and peach varieties (Prunus persica). Plant Mol. Biol. Rpt. 17:255-267.

Ming, J. and Q. Zhang. 2003. Identification of Meiflower cultivars using AFLP fingerprint (in Chinese). J. Beijing For. Univ. 25(Spec.):46-48.

Moore, J.N., R.C. Rom, S.A. Brown, and G.L. Klingaman. 1993. 'Bonfire'dwarfpeach, 'Leprechaun' dwarf nectarine, 'Crimson Cascade' and 'Pink Cascade' weeping peaches. HortScience 28:854.

Pejic, I., P. Ajmone-Marsan, M. Morgante, V. Kozumplick, P. Castiglion, G. Taramino, and M. Motto. 1998. Comparative analysis of genetic similarity among maize inbred lines detected by RFLPs, SSRs, and AFLPs. Theor. Appl. Genet. 97:1248-1255.

Pooler, M.R. 2003. Molecular genetic diversity among 12 clones of Lagerstroemia fauriei revealed by AFLP and RAPD markers. HortScience 38:256-259.

Powell, W., M. Morgante, C. Andre, M. Hanafey, J. Vogel, S. Tingey, and A. Rafalski. 1996. The comparison of RFLP, RAPD, AFLP, and SSR markers for germplasm analysis. Mol. Breed. 2:225-238.

Russell, J.R., J.D. Fuller, M. Macaulay, B.J. Hatz, A. Jahoor, W. Powell, and R. Waugh. 1997. Direct comparison of level of genetic variation among barley accessions detected by RFLPs, AFLPs, SSRs, and RAPDs. Theor. Appl. Genet. 95:714-722.

Shimada, T., T. Yamamoto, H. Yaegaki, M. Yamaguchi, M. Yoshida, and T. Hayashi.1998. Application of AFLP to molecular genetic analysis in peach. J. Jpn. Soc. Hort. Sci. 68(1):67-69.

Struss, D., M. Boritzki, K. Glozer, and S.M. Southwick. 2001. Detection of genetic diversity among populations of sweet cherry (Prunus avium L.) by AFLPs. J. Hort. Sci. Biotechnol. 76:362-367.

Struss, D., R.Ahmad, S.M. Southwick, and M. Boritzki. 2003. Analysis of sweet cherry (Prunus avium L.) cultivars using SSR and AFLP markers. J. Amer. Soc. Hort. Sci. 128: 904-909.

Swofford, D.L. 2002. PAUP, phylogenetic analysis using parsimony. version 4.0b10. Sinauer, Sunderland, Mass.

Tavaud, M., A. Zanetto, F. Santi, and E. Dirlewanger. 2001. Structuration of genetic diversity in cultivated and wild cherry varieties using molecular markers. Acta Hort. 546:263-269.

Tomkins, J.P., T.C. Wood, A. Westman, and R.A. Wing, 2001. Evaluation of genetic variation in the daylily (Hemerocallis spp.) using AFLPmarkers. Theor. Appl. Genet. 102:489-496.

Vos, P., R. Hogers, M. Bleeker, M. Reijans, T. van de Lee, M. Hornes, A. Frijters, J. Pot, J. Peleman, M. Kuiper, and M. Zabeau. 1995. AFLP: A new technique for DNA fingerprinting. Nucleic Acids Res. 23:4407-4414.

Werner, D.J., S.M. Worthington, and L.K. Snelling. 2000a. Peach tree named 'Corinthian Mauve' U.S. Patent PP11576.

Werner, D.J., S.M. Worthington, and L.K. Snelling. 2000b. Peach tree named 'Corinthian Rose'. U.S. Patent PP11504.

Werner, D.J., S.M. Worthington, and L.K. Snelling. 2000c. Peach tree named 'Corinthian White'. U.S. Patent PP11493.

Werner, D.J., S.M. Worthington, and L.K. Snelling. 2001. Peach tree named 'Corinthian Pink'. U.S. Patent PP11902.

Yamazaki, K., M. Okabe, and E. Takahashi. 1987. New broomy flowering peach cultivars 'Terutebeni', 'Terutemomo', and 'Teruteshiro' (in Japanese). Bul. Kanagawa Hort. Expt. Sta. 34:54-56.

Yoshida, M. and K. Seike. 1974. 'Red Dwarf', the new red-dwarf peach (in Japanese). Bul. Fruit Tree Res. Sta. A(1):25-32.

Yoshida, M., K. Yamane, Y. Ijiro, N. Fujishige, M. Yamaguchi, and E. Takahashi. 2000. Studies on ornamental peach cultivars. Bul. College Agr. Utsunomiya Univ. 17(3):1-14.

Zhang, C. 1998. Studies on evolution relationships between ornamental peach cultivars (in Chinese). MS thesis. Beijing For. Univ.

Zhang, D., M.A. Dirr, and R.A. Price. 2000. Discrimination and genetic diversity of Cephalotaxus accessions using AFLP markers. J. Amer. Soc. Hort. Sci. 125:404-412.

Zhang, X., Y. Wang, and G. Wang. 1997. Observation and comparisons on the pollen morphology of peach-blossom cultivars germplasm resources (in Chinese). J. Beijing For. Univ. 19(2):57-62.

Zhou, C. and S. Dai. 2002. Analysis on Dendrathema using AFLP (in Chinese). J. Beijing For. Univ. 10:71-75.

Zhou, L., F. Kappel, C. Hampson, P.A. Wiersma, and G. Bakkeren. 2002. Genetic analysis and discrimination of sweet cherry cultivars and selections using amplified fragment length polymorphism fingerprints. J. Amer. Soc. Hort. Sci. 127:786-792. 